\title{
Aprendizagem Intercultural por meio de Imersão Musical
}

\author{
Antenor Ferreira Corrêa \\ (UNB) \\ Maria Westvall \\ (Örebro University)
}

Resumo: discussão a respeito de abordagens interculturais relacionadas às propostas de uma educação para a diversidade. Interrogam-se aspectos relativos à incorporação no currículo escolar de conteúdos provenientes de manifestações populares típicas dos diferentes países que visam atender às demandas por uma educação intercultural. 0 artigo norteia-se pela questão: como poderíamos experimentar um diálogo intercultural no contexto da música? Para tanto, são apresentados os conceitos de interculturalidade, multiculturalidade e transculturalidade. A seguir, apresentam-se resultados parciais de uma pesquisa em andamento intitulada Processos Interculturaisde Ensino-Aprendizagem com o objetivo de embasar as reflexões em torno da interculturalidade, que no orbe desse projeto, foi realizada por meio de imersão musical.

Palavras-chave: interculturalidade, multiculturalidade, transculturalidade, imersão musical.

\section{INTERCULTURAL LEARNING THROUGH MUSIC IMMERSION}

Abstract: at this article, we discuss about intercultural approaches related to the idea of an education for diversity. We consider some aspects regarding the presence of traditional music from different cultures in the academic curriculum. We propose the following question: how would one experiences an intercultural dialogue within the area of music? In this sense, we introduce concepts of interculturality, multiculturality, crossculturality, and music immersion. After that, we present partial results of an ongoing collaboration between Örebro University (Sweden) and University of Brasília (Brazil) titled Processes of Intercultural teaching and learning: Research, Online collaboration, and Musical Immersion in Brazil and Sweden, which here was taken as means to bear reflections about intercultural education, which within that project, was accomplished by means of music immersion.

Keywords: interculturality, multiculturality, crossculturality, music imersion. 


\section{Introdução}

No contexto educacional, observa-se um esforço frequente para absorver no interior do currículo escolar práticas musicais da cultura tradicional. Essa atitude pode ser notada, por exemplo, pela criação de disciplinas como etnomusicologia, world music, folclore, entre outras. Esse fato já vem de longa data e não é o propósito deste texto discutir ou justificar essa recontextualização de conteúdos. No entanto, há cerca de vinte anos, esse assunto tem sido retomado por conta de uma necessidade sentida, particularmente nos Estados Unidos e Europa (principalmente por conta do aumento das imigrações), da proposição de uma educação para a diversidade, que traz implícita a adoção de um pensamento multicultural na educação. Posto de outro modo, a questão da incorporação no currículo escolar de conteúdos provenientes de manifestações populares típicas das diferentes culturas tem sido revista em razão das demandas por uma educação multicultural.

Estendendo-se o tema para a área de música, entende-se que uma educação para a diversidade também implicaria, ou ao menos consideraria apropriado como ponto de partida, uma abordagem multicultural para o ensino da música, abarcando no interior dos currículos, o repertório musical tradicional de diferentes culturas. Todavia, no interior da estrutura da educação musical, isto não apenas desafia a escolha do repertório (que geralmente relaciona-se com o cânone europeu), mas também abre para a diversidade de métodos e práticas interpretativas dentro do contexto educativo.

Essa atitude gerou e tem gerado posicionamentos favoráveis. Todavia, também tem recebido críticas, sobretudo pelo fato de que essa iniciativa exigiria um professor conhecedor de inúmeras tradições culturais. Ainda, os críticos assinalam que, mesmo com a adoção de livros cujo teor verse sobre um número relativamente grande de manifestações musicais distintas, como é o caso de livros didáticos na área da world music (Cf., por exemplo, Miller \& Shahriari, 2006), vários aspectos por demais importantes e significativos ficariam sem explanações e sem serem apropriadamente contextualizados. 
As críticas lançadas sobre a abordagem multicultural na educação musical são possíveis de serem compreendidas, pois é fácil notar que em muitos dos domínios culturais sobre os quais o docente teria que lecionar, ele/a seria um tipo de outsider. Desse modo, não haveria a possibilidade de aprofundar-se em todos aspectos relevantes das diferentes tradições requeridas pelo currículo acadêmico. Desse modo, "a superficialidade acabaria por comprometer a qualidade do curso, pois como outsider, [o professor] não poderia promover insights significativos às diversas tradições musicais, já que para uma compreensão profunda das diferentes culturas, seria necessário uma vivencia prolongada nos distintos contextos". (Regelsky, 2010, p. 96). Alberto Ikeda, em um artigo no qual aborda questões sobre as premiações que o governo brasileiro tem distribuído no campo da “cultura popular", pondera sobre o orbe complexo envolvido nas manifestações culturais tradicionais, âmbito este muito difícil de ser totalmente dimensionado quando se pensa sobre critérios a serem adotados para tais premiações. Sua reflexão, embora originalmente não tivesse destinada à discussão proposta neste texto, servirá aqui para auxiliar o entendimento da fundamentação das críticas lançadas à educação multicultural.

Há de se considerar que os fenômenos das culturas tradicionais guardam valores morais, religiosos, políticos, lúdicos, estéticos e outros tantos, que foram herdados e, portanto, de algum modo refletem a própria história das suas comunidades, repondo o passado no presente, e sendo então sempre atuais. São práticas aglutinadoras, que, repetidas ciclicamente, reforçam os valores socialmente aceitos e importantes para os grupos, vitalizando-os. Por serem fatos preservados e geridos coletivamente, são instrumentos de identidade e inclusão social, e até mesmo de resistência política diante dos problemas que as comunidades enfrentam. (IKEDA, 2011, p. 69)

Certamente, toda música é inseparável do contexto social no qual foi gerada. E o postulado de que a música pode ser compreendida em 'si mesma' foi rebatido mesmo entre os musicólogos ${ }^{1}$. Logicamente, toda música também pode

\footnotetext{
1 Sobretudo após os trabalhos ligados à chamada Nova Musicologia, a obra musical foi pensada a partir de seu conteúdo ideológico implícito. Neste sentido, discussões sobre gênero (que ganharam notoriedade após os estudos de Susan McClary) e cultura ascenderam em importância. Os próprios proponentes dessa nova postura musicológica, como Lawrence Kramer, Richard Leppert e Rose Subotnik, defenderam que a melhor
} 
ser apreciada sem que o ouvinte tenha a menor noção a respeito do contexto da composição da obra; embora, o estranhamento de uma primeira audição de músicas de outro domínio cultural pode agir no juízo de gosto, fazendo com que um auditor declare "não ter gostado de determinada música" justamente por conta da sua falta de familiaridade com a mesma ou por não ter uma noção mais abrangente da conjuntura a qual a obra pertence. Vale lembrar que toda audição é histórica, pois ouvir remete ao repertório identificado como "música" que temos armazenado na memória.

No entanto, em uma sociedade culturalmente diversificada, poderiam haver várias maneiras de se relacionar com a aprendizagem musical, e as aulas de música também podem ter o potencial de fornecer um contexto de aprendizagem alternativo, como Kwami (2001) sugere:

O fato de que o contexto de sala de aula é diferente do contexto cultural de qualquer música pode tornar possível e assegurar a aplicação de oportunidades igualitárias em relação a questões tais como gênero, raça, religião, e assim por diante. Por exemplo, as meninas poderiam tocar instrumentos que não lhes são permitidos executar em um contexto tradicional (Kwami, 2001, p. 151).

Não obstantes tais posicionamentos, abordagens multiculturais (ou interculturais, como se verá adiante) foram e continuam sendo adotadas no ambiente educacional. Alinhados a esses posicionamentos, no presente artigo intentaremos demonstrar que esse modelo conceitual contribui para a formação global do estudante de música. Essa demonstração fundamenta-se em resultados parciais de um projeto de pesquisa em andamento realizado no âmbito de um acordo de cooperação internacional patrocinado pelas fundações CAPES, governo brasileiro, e pela STINT, governo sueco. Nosso objetivo não é defender ou criticar abordagens interculturais, mas sim identificar aspectos relevantes para o ensino aprendizagem da música surgidos a partir do que denominamos imersão musical. Assim, cremos que o objeto de estudo principal desta pesquisa são os "processos interculturais de ensino-aprendizagem". Ao longo do texto, conceitos como

denominação para a corrente da New Musicology seria Musicologia Cultural (Cf. Kramer, 2003, p. 6). 
multiculturalismo, interculturalidade, transculturalidade serão apresentados e discutidos, sempre a partir da ótica da educação musical. Ainda, quando oportuno e necessário à clareza da exposição, serão oferecidas breves descrições das atividades promovidas durante o projeto.

\section{Intercultural, Multicultural e Transcultural}

O prefixo 'inter' provem do latim e significa 'entre'. É utilizado na composição de várias palavras não só em língua portuguesa. Desse modo, intercâmbio, por exemplo, refere-se à troca entre dois locais ou instâncias distintas, e internacional é o que se realiza entre nações. Por sua vez, intercultural significa a mútua influência entre culturas diferentes. Não há, pois, a restrição de que essas culturas em interação devem ser de nações ou nacionalidades distintas. O processo intercultural, desse modo, pode ocorrer, também, pela interação entre contextos culturais de um mesmo país. Todavia, é importante observar que a interculturalidade ocorrerá quando duas culturas interagirem de forma mutuamente cooperativa, ou seja, não deve haver relação de passividade entre as culturas em ação. Vale esclarecer que 'interação' refere-se, portanto, às ações e relações entre os membros de um grupo ou entre grupos de uma sociedade ou de nações.

O entendimento de interação motivou alguns cientistas a lançarem nova abordagem para explicar o comportamento social, enfoque este denominado interacionismo. Herbert Blumer, por exemplo, já em 1937, em um artigo intitulado Man and Society, fundamentou o interacionismo simbólico com base em três premissas: 1) o modo como um indivíduo interpreta os fatos e age perante outros indivíduos ou coisas depende do significado (ou significados) que ele atribui a esses outros indivíduos e coisas. 2) o significado, porém, é resultado dos (ou é construído a partir dos) processos de interação social. E 3) os significados podem sofrer mudanças ao longo do tempo (Blumer, apud Cancian, 2009). 
Abordagens como esta, esclarecem e reforçam o fato de que o processo interativo, e por conseguinte, as ações interculturais, tratam-se de sistemas dialéticos, já que os coletivos formados no âmbito de quaisquer contextos sociais são criados por pessoas, que posteriormente serão afetadas pelo grupo que criaram. Renato Cancian coloca essa conclusão desse modo: "a ação dos atores é derivada da significação; essa significação deriva ou surge das interações sociais; por fim, as significações são empregadas pelos atores sociais nas interações sociais grupais, que, por sua vez, modificam as próprias significações" (Cancian, 2009). Esse esclarecimento nos ajuda aqui a aprofundar a compreensão da complexidade envolta no conceito de interculturalidade.

O prefixo 'multi', por sua vez, tem acepção de 'muitos(as)'. Assim, multiplicar, por exemplo, significa produzir em grande quantidade. Neste sentido, multicultural implicaria na coexistência de muitas culturas. Percebe-se, portanto, que o conceito de multiculturalidade não traz obrigatoriamente implícito a necessária interação entre as culturas, mas apenas expressa uma relação de quantidade. De início, o conceito de "educação musical multicultural foi usado para descrever ambos: o ensino de música de diversas origens culturais e o ensino de música para estudantes de distintos contextos culturais" (Hebert e Karlsen, 2010, p. 8). Porém, talvez justamente por não indicar a interatividade desejada entre os sujeitos componentes desse contexto educativo, "o termo educação 'multicultural' foi modificado para educação 'intercultural' de modo a destacar que o objetivo não é a mera coexistência, mas sim, a cooperação e o aprendizado frutífero e igualitário entre culturas" (Räsänen, 2010, p. 12). Este autor destaca que esse tipo de interação tem por base a equidade e o respeito mútuo, ou seja, idealmente não deve haver relação hierárquica entre os lados. Há ainda a necessidade de que o diálogo intercultural desenvolva o aprendizado intercultural, sendo este o desenvolvimento do entendimento do contexto particular de cada cultura e, também, da compreensão daquilo que é representativo e significativo da outra cultura (Cf. Räsänen, 2010, p. 17).

É útil para uma compreensão ampla do conceito de interculturalidade, também pensarmos sobre a ideia de transculturalidade (Lundberg \& Ternhag 2002; Schippers 2010). Se o prefixo 'inter' refere-se àquilo que vai entre, 'trans' 
refere-se, por sua vez, ao que vai 'através'. Talvez, por conta dessa acepção semântica, a ideia de interdisciplinaridade ganhou predominância no ambiente acadêmico em detrimento de abordagens transdisciplinares. Todavia, obviamente as duas abordagens podem contribuir relevantemente para o processo educativo. Com esse entendimento, uma abordagem transdisciplinar adquire um teor mais passivo, justamente por não comportar a exigência da interação presente em processos interdisciplinares. No entanto, no orbe de um processo transcultural, mesmo dedicando-se se a destacar particularidades de contextos culturais diversos, é possível obter resultados significativos. As similaridades observadas em diferentes contextos, por exemplo, podem apontar para fundamentos subjacentes comuns. Esses fundamentos poderiam, então, ser pensados como padrões ou constâncias e ser utilizados para a elaboração de constructos teóricos de alcance mais geral, derivados, neste caso, dos contextos particulares. Observar padrões e procedimentos similares poderia propiciar, por exemplo, justificativas de base psicológica ou cognitiva para as práticas culturais, permitindo, também, a derivação de construtos de ordem geral (Cf. Hanson, 1999). Tendo em mente as diferenças entre essa terminologia, prosseguiremos com uma descrição sumária de um projeto de cooperação internacional que tem a interculturalidade como base conceitual.

\section{Imersão Musical e Interculturalidade}

Nos últimos quatro anos, alguns professores e alunos têm participado de um projeto de intercâmbio ao nível da graduação promovido entre as Universidades de Örebro (Suécia) e de Brasília (Brasil). Essa parceria internacional revelou-se bem sucedida, por uma série de confluências, contingências e interesses entre os envolvidos. Este fato motivou-nos a tentar ampliar essa colaboração de modo a abarcar projetos de pesquisa em nível de pós-graduação. Essa extensão foi possibilitada em 2013 por conta de um Edital de cooperação internacional lançado pela CAPES e outra fundação sueca: STINT - Stiftelsen for Internationalisering av Högre Utbildning och Forskning (Fundação Sueca para 
Cooperação Internacional e Pesquisa em Educação Superior). E foi no âmbito desse edital que aprovamos um novo projeto intitulado Processes of Intercultural Teaching and Learning: Research, Online Collaboration, and Musical Immersion in Brazil and Sweden, cujos resultados parciais conseguidos na primeira fase de sua implantação ajudarão a embasar as reflexões a seguir referentes ao processo das ações interculturais, focando, contudo, no que denominamos imersão musical.

O projeto fundamenta-se em propostas lançadas por educadores ligados à temática do ensino aprendizagem intercultural. Diversos autores já escreveram sobre o tema. Aqui, de modo objetivo, especificam-se apenas três destes, por entender-se que a apreensão do conceito é o mais importante neste momento.

Entende-se de modo sumário que a aprendizagem intercultural acontece e implica na interação entre pessoas e a cultura. Compartilhando desse postulado, Yoshitaka Yamazaki (2004) e D. Christopher Kayes, por exemplo, descreveram espécie de taxonomia das habilidades necessárias para a aprendizagem intercultural, alicerçados em pesquisas bem estabelecidas do campo da Teoria da aprendizagem vivencial. Realizaram, também, revisão da literatura empírica e identificaram as habilidades que convergem para a aprendizagem intercultural temática. Boyatzis \& Kolb (1991) detalharam os processos de aprendizagem transcultural de expatriados e imigrantes, e os mecanismos implicados nesses procedimentos alheios a quaisquer sistemas educacionais formais. Maria Westvall (coordenadora deste projeto) escreve em parceria com Suzanne Burton e Samuel Karlsson em seu artigo Stepping Aside From Myself: Intercultural Perspectives on Music Teacher Education (2013) acerca das experiências compartilhadas entre estudantes de educação musical participantes de um curso de educação musical intercultural que incluía imersão musical e educacional na Suécia e Estados Unidos.

O projeto envolve também a área de antropologia cultural. Neste sentido, a relevância é dada à experiência do pesquisador em campo, de modo a possibilitar a observação direta do comportamento individual no seio da comunidade social onde convive e na qual as manifestações artístico/musicais são aprendidas, executadas e transmitidas. Como bem mostrou Laplantine, o observador é parte integrante do objeto de estudo. A suposta neutralidade do 
observador em prol da pretensa objetividade "retira dos resultados de sua pesquisa tudo o que contribuiu para sua realização" (Laplantine, 2007, p. 169). Isso ocorre por conta de uma característica essencial das ciências sociais, onde "incluir-se não apenas socialmente mas subjetivamente faz parte do objeto científico que procuramos construir, bem como, do modo característico da profissão do etnólogo" (idem, p. 173).

Em sintonia com esses fundamentos, os pesquisadores envolvidos no projeto devem tomar parte no que definimos como imersão musical. Assim, temse a intenção de efetivar as ideias advindas dos processos interculturais pesquisados, constituindo uma vertente eminentemente prática advinda e embasada nas vivências e pesquisas de campo. Dito de outro modo, esta imersão refere-se à realização de viagens de campo especialmente planejadas pelas instituições parceiras que ocorrem em áreas de reconhecida diversidade cultural, onde saberes tradicionais são mantidos e praticados quer sejam por associações e/ou comunidades musicais ou no orbe de projetos sociais ligados à área da educação musical. Durante o período de imersão, o investigador não somente deve realizar pesquisa de campo nos moldes metodológicos etnográficos conhecidos, mas também interagir no contexto sócio musical tocando e ensinando sua própria música tradicional. Esta imersão musical, por meio de seu aspecto intercultural distintivo, contribui para o compartilhamento de novos conhecimentos nas áreas de etnomusicologia e educação musical, enfatizando, também, processos gerais de ensino aprendizagem. Além disso, cremos que o projeto tem potencial para contribuir para o desenvolvimento de novos métodos de ensino-aprendizagem baseados em abordagens interculturais integrativas através do compartilhamento das experiências de campo realizados pelos envolvidos.

O projeto foi estruturado de acordo com alguns objetivos principais para o desenvolvimento de pesquisa e aperfeiçoamento de professores e estudantes. A seguir, mencionamos de forma sucinta alguns destes objetivos: 1) implantar um curso de imersão cultural entre os dois departamentos de pesquisa. Desse modo, durante o período de vigência deste projeto, cada estudante envolvido irá, por 20 dias, atender a esse curso oferecido pelo Programa de Pós-Graduação da 
Universidade parceira. Além disso, os estudantes irão participar de três atividades específicas adicionais, em distintas regiões da Suécia e do Brasil, que estão relacionadas com dois projetos de pesquisa desenvolvidos pelos coordenadores dessa proposta Maria Westvall (Music, identity, and multiculturalism: A study of the role of music in ethnic-based associations) e Antenor Ferreira Corrêa (Gêneros Musicais Brasileiros: mapeamento e análise). 2) Estruturar sistema de colaboração online entre os programas de pós-graduação das Universidades de Örebro e de Brasília. 3) Desenvolver pesquisa conjunta entre os professores participantes. 4) Participar de eventos científicos apresentando os resultados do projeto.

Ao encontro desses objetivos, as atividades de imersão cultural configuram-se como essenciais no sentido de motivarem e inspirarem alunos e professores a buscarem atitudes e abordagens inovadoras em suas respectivas áreas de atuação. Há vários pesquisadores envolvidos diretamente no projeto (incluindo dois estudantes de doutorado e pós-doutorado e pesquisadores seniores), além de um grupo significativo de estudantes de mestrado e doutorado que estarão também ligados a este empreendimento. Esta condição permite uma oportunidade única para experiências interculturais práticas e teóricas, o que poderá contribuir para o desenvolvimento de novos conhecimentos e ampliar perspectivas no campo da educação e da etnomusicologia. Consequentemente, essas experiências interculturais fortalecerão o ambiente de pesquisa em cada instituição. Além disso, a pesquisa colaborativa, bem como atividades de ensino e aprendizagem (seminários e workshops) programados para as duas instituições deverão desenvolver-se e tornarem-se mais consolidados.

No caso do projeto descrito, o conceito de interculturalidade pode ser definido como o processo interativo e as interações pessoais dos dois contextos culturais participantes. Esse entendimento valida-se não apenas quando refere-se às relações entre pesquisadores brasileiros e suecos, mas também ao abarcar as interações ocorridas entre as várias culturas tradicionais particulares do Brasil e da Suécia. A principal variante é que o foco recai sobre os encontros reais envolvendo pessoas, músicas e pessoas e música.

Grosso modo, o compartilhamento de experiências, quando relacionado ao conceito de culturalidade, pode ser visto como um fim em si mesmo. Todavia, 
“as relações internacionais e interculturais não são somente um único ideal a ser objetivado, mas antes podem propiciar realidades e contextos de aprendizagem muito produtivos [...] Culturas nacionais têm sido enriquecidas por influencias interculturais, e movimentos sociais tem se disseminado de um continente para outro" (Räsänen, 2010, p. 13). Percebe-se, que o contato entre músicos/ pesquisadores de diferentes nacionalidades produz resultados que extrapolam o orbe iminentemente musical. Deste modo, questões próprias da área da música apresentam-se como motivadores do aprofundamento das reflexões sobre interculturalidade. Como poderíamos experimentar um diálogo intercultural no contexto da música? Talvez uma resposta é trabalhar no desenvolvimento de acordos curriculares e procedimentais mais amplos e diversificados na área de educação musical formal (Westvall \& Carson, 2014) relacionados com a incorporação de vários repertórios e aspectos da música e, também, das experiências compartilhadas.

\section{Considerações finais}

Professores e pesquisadores (na sua grande maioria) estão inseridos no contexto acadêmico universitário. As universidades brasileiras (e sueca, no caso aqui em apreço), por sua vez, compartilham em maior ou menor grau, projetos políticos pedagógicos análogos aos modelos europeus e norte-americano. Neste paradigma estrutural, o domínio do conhecimento na área de atuação do professor/pesquisador é comprovado por títulos ou graus acadêmicos referendados pelas próprias instituições universitárias de pesquisa, já que títulos e graus de mestre e doutor são concedidos pela própria universidade. A obtenção de títulos se dá após defesa de tese ou dissertação, na qual o pesquisador versa sobre um objeto de pesquisa específico, pois é praticamente impossível a uma única pessoa dar conta de todo o conteúdo de uma área do conhecimento. Desse modo, "os saberes individuais estritos vão se sobrepondo aos saberes comunitários latos. A problemática se estabelece ao dar-se conta de que o saber social é muito maior que o saber institucionalizado da universidade" (Corrêa, 2011). O projeto 
aqui descrito foi uma maneira que encontramos para tentar lidar e, esperançosamente, amenizar essa situação, posto que durante o período de imersão musical o pesquisador ficou exposto às tecnologias comunitárias de cunho mais amplo.

Obviamente, temos em mente um entendimento amplo de tecnologia, na qual também se encontra compreendido o conceito de tecnologias intelectuais, que envolve os artifícios e estratégias promotores ou viabilizadores de procedimentos de raciocínio diferenciado. Trata-se, por exemplo, de gerar novos e distintos "olhares" sobre os problemas. Isso baseia-se no fato de que o aparato cognitivo humano envolve as formas e meios pelos quais nos damos conta da realidade, bem como a maneira como interpretamos o mundo. É preciso lembrar que não somente o cérebro está envolvido nesse mecanismo de formatação, significação e compreensão da realidade, mas também o corpo como um todo age como mediador e viabiliza a percepção de estímulos e informações do meio. A partir dessa rede cognitiva formamos nossa compreensão das coisas e criamos conceitos e constructos que levam a explicar os fenômenos observados. Toda essa estrutura perceptiva e intelectiva fundamenta a criatividade humana, que poderá, naturalmente, ser desenvolvida ou atrofiada. De toda essa situação é possível perceber a importância fundamental que o meio, o contexto no qual nos inserimos, exerce na consolidação da aprendizagem e conhecimento. E é justamente por conta desse papel relevante que o fato de vivenciar in loco uma cultura diferente pode promover aos indivíduos contingências que lhes permitirão abertura perceptual, isto é, olhares renovados sobre antigas questões, levando a ações inovadoras e criativas. E claramente, a experiência com uma realidade cultural distinta pode ser atingida com a realização de estudos e pesquisas interculturais. A oportunidade de interação cultural revela aos envolvidos aspectos subjetivos importantes, porém normalmente relegados ao segundo plano justamente por serem difíceis de quantificar ou por não gerarem produtos físicos observáveis. E advogamos que essa parte subjetiva advinda da experiência internacional deve sempre fazer parte de discussões sobre a proposta de uma educação para a diversidade. 
O contato com grupos de cultura tradicional levou-nos também a pensar sobre as metodologias de ensino adotadas nas universidades. Já na criação oficial das primeiras universidades brasileiras evidenciou-se a importação de um modelo advindo, sobretudo, da "concepção francesa da universidade napoleônica, principalmente em relação às características de escola autárquica, com a supervalorização das ciências exatas e tecnológicas, voltadas para a profissionalização, e a desvalorização da filosofia, da teologia e das ciências humanas (Ribeiro, 1975). A metodologia importada de modelos europeus ou norte-americanos leva ao estabelecimento de um modo particular de construção de conhecimento, ressaltado pelo aspecto de que coloca o docente em posição central e centralizadora desse processo, posto que o mesmo se responsabiliza pela escolha e disseminação dos conteúdos. No orbe da transmissão dos saberes tradicionais, por sua vez, a aquisição do conhecimento ocorre de modo mais participativo, resultando da interação entre os participantes, mestres de cultura popular e, também, da comunidade como um todo. Ainda, a adoção de modelos eurocêntricos interferiu e interfere na seleção dos conteúdos a serem ministrados nas respectivas disciplinas. "A utilização desse padrão levou à exclusão do currículo disciplinar de conteúdos oriundos do saber, fazer e sentir próprios das concepções populares (ligadas em maior ou menor grau a processos informais e de transmissão oral de ensino e aprendizagem)" (Corrêa, 2011). Neste ponto, entendemos que os saberes tradicionais, bem como seus procedimentos de transmissão e processos de aprendizagem inerentes, constituem um valioso corpus teórico-prático que deve ser melhor compreendido. E foi justamente sobre esse aspecto que a imersão musical revelou-se interessante, pois evidenciou certas qualidades não comportadas pelas metodologias em voga nas universidades. Esse resultado será descrito a seguir exemplificado pelo encontro e pela interação entre pesquisadores e um grupo de Congada de Moçambique.

Na leitura de algumas dissertações, temos notado que, em várias vezes, os autores procuram justificar as pesquisas realizadas em grupos de cultura tradicional pela afirmação de que se trata(m) de grupo(s) tradicional da cidade, detentor(es) de manifestações folclóricas consagradas, algumas vezes em via de extinção, e que por isso merecem ser estudadas e preservadas. Sem entrar no 
mérito de tais justificativas, entendemos que, além das históricas, existem razões educacionais para se pensar e validar uma pesquisa em grupos de cultura tradicional. As manifestações musicais populares que envolvem gêneros tradicionais formam um importante corpus teórico e prático que deve ser conhecido pelos estudantes de música, sejam estes do bacharelado ou da educação musical. Somado aos aspectos sociais, históricos e contextuais, para os instrumentistas o conhecimento desses gêneros musicais auxiliará na execução e interpretação mais fundamentadas desse repertório, que inclusive, ganhou espaço no repertório sinfônico ligado ao nacionalismo, mas cada vez mais tem frequentado as salas de concerto promovido pela simbiose e inspiração dos compositores com elementos da música popular. Para os futuros educadores, por sua vez, esses gêneros musicais poderão servir como possíveis estratégias didáticas na medida em que o docente poderá valer-se de elementos conhecidos da cultura popular para transmitir conceitos musicais não tão familiares aos alunos. Neste sentido, o professor pode fazer uso didático dos procedimentos e práticas de ensino informal próprios dos contextos da oralidade. Associado a estes aspectos, concorre o desenvolvimento integrado de diversas habilidades, como por exemplo, cognitivas, psicomotoras e da coordenação e independência motoras.

Em um dos momentos da imersão musical, pesquisadores participaram de um grupo de Congada de Moçambique. A Congada apresenta grande difusão pelo território nacional. Há grupos de congada em atuação de norte a sul do país. Esse gênero é melhor definido como tratando-se de um folguedo ou auto popular que dramatiza cênica, coreográfica e musicalmente lutas entre nações africanas, por vezes denominadas de embaixadas. Dentre os elementos característicos desse gênero destacam-se a música, a dança, o enredo e as narrativas, a crença, a dramaturgia com cenografia, figurinos e adereços. Como pesquisadores em música, obviamente nos interessa conhecer sobre a música. Assim, buscamos saber o que é tocado, por quais instrumentos, como são tocados os instrumentos, como se faz e por que se faz o Moçambique. No entanto, um dado relevante se nos apresentou durante o contato com a Congada, a saber: o conjunto de habilidades exigida dos participantes que desejam atuar como como congueiros. Deve-se memorizar elaboradas coreografias realizadas com os bastões em sincronia com a 
música, passos de dança, a letra das canções e, para os que representam personagens, seus respectivos textos. Aqueles que tocam, por seu turno, devem permanecer atentos a todas as partes dessa dramaturgia de modo a realizarem as intervenções musicais no momento correto, ou seja, devem estar integrados ao folguedo, e não agindo como meros coadjuvantes. Nota-se, então, que a transmissão oral dessa tradição não é empresa fácil. Essa característica exige dos participantes a confluência de várias aptidões, pois precisam lembrar-se dos passos, textos, letras à medida que manejam bastões e dançam no ritmo da música.

A imersão musical neste e em outros contextos tradicionais, propiciou a integração e coexistência dos saberes tradicionais e acadêmicos em uma abordagem intercultural. Neste percurso, aspectos educacionais subjetivos advindos dos processos de aprendizagem solidária, do compartilhamento de saberes, da construção coletiva do conhecimento, da disposição e disponibilidade em auxiliar-se mutuamente, foram evidenciados. Infelizmente, estes valores têm sido perdidos, pois o isolamento individual parece ser uma característica da nossa sociedade contemporânea. Basta ver, por exemplo, que a grande maioria das crianças, mesmo em cidades interioranas, são criadas no interior das residências em frente a videogame, computador ou TV, seja por questões de segurança ou necessidade dos pais.

Bruno Nettl (2005) defendia que a tarefa do etnomusicólogo seria de empreender o máximo esforço possível para tentar "abarcar os modos de interação entre música e cultura em uma determinada comunidade". John Shepherd (1991), por sua vez, reformulava a questão ao procurar compreender “em que medida as estruturas e práticas musicais refletem, modelam ou ressoam identidades, experiências, ou posições estruturais de classes sociais, gêneros e grupos étnicos?”. A área e subáreas da música já caminharam um longo percurso ao encontro de tais respostas. $E$, no âmbito desta iniciativa, entendemos que a interculturalidade pode oferecer situações e procedimentos para avançarmos um pouco mais nessa jornada. 


\section{Referências}

BOYATZIS, R. E., \& KOLB, D. A. Assessing Individuality in Learning Skills Profile. In: Educational Psychology, 11 (3-4), 1991, p. 279-295.

BURTON, Suzanne, WESTVALL, Maria \& KARLSSON, Samuel. Stepping Aside From Myself: Intercultural Perspectives on Music Teacher Education. Journal of Music Teacher Education, 2013.

CANCIAN, Renato. In: Interacionismo Simbólico - fundamentos: Blumer e o estudo das Interações Sociais. Especial para a Página 3 Pedagogia \& Comunicação. Disponível em: http://educacao.uol.com.br/disciplinas/sociologia/interacionismosimbolico---fundamentos-blumer-e-o-estudo-das-interacoes-sociais.htm

CORRÊA, Antenor Ferreira. Encontro dos Saberes Tradicionais: uma alternativa ao colonialismo metodológico. In: Anais da 1ra Conferencia Regional Panamericana de La Sociedad Internacional de Educación Musical, ISME/ Universidad Juárez Autónoma de Tabasco. Villahermosa, México, 2011.

HANSON, Barbara. The Research Process: Creating Facticity. Illinois: Waveland Press, 1999.

HEBERT, David G. and KARLSEN, Sidsel. Editorial Introduction: Multiculturalism and Music Education. In: Musiikkikasvatus - The Finnish Journal of Music Education. Vol, 13, No.1. Hakapaino: Helsinki, 2010, p. 6-11.

IKEDA, Alberto. Folia de Reis, Sambas do Povo. Coleçao Cadernos de Folclore. Vol. 21. Sao José dos Campos: Fundaçao Cultural Cassiano Ricardo, 2011.

KRAMER, Lawrence. Musicology and Meaning. In: The Musical Times. Vol. 144, No. 1883, 2003, p. 6-12. Disponível em: http://www.jstor.org/stable/3650677

KWAMI, Robert. M. Music Education In and For a Pluralist Society. In C. Philpott \& C.Plummeridge (Eds.) Issues in Music Teaching. London: Routledge/ Falmer, 2001, p. $142-155$.

LAPLATINE, François. Aprender antropologia. São Paulo: Brasiliense, 1988.

LUNDBERG, Dan \& TERNHAG, Gunnar. Musiketnologi: en introduktion. Hedemora: Gidlund, 2002.

MILLER, Terry E. and SHAHRIARI, Andrew. World Music: A Global Journey. New York, Routledge, 2006.

NETTL, Bruno. The meat and potatoes book: musical ethnography. In: The Study of Ethnomusicology: Thirty-one Issues and Concepts. University of Illinois Press, 2005.

RÄSÄNEN, Rauni. Intercultural Education and Education for Global Responsibility in Teacher Education. In: Musiikkikasvatus - The Finnish Journal of Music Education. Vol, 13, No.1. Hakapaino: Helsinki, 2010, p. 12-24. 
REGELSKI, Thomas A. Culturalism, Multi-Culturalism, and Multi-Musical Prosperity. In: Musiikkikasvatus - The Finnish Journal of Music Education. Vol, 13, No.1. Hakapaino: Helsinki, 2010, p. 95-98.

RIBEIRO, Darcy. A Universidade Necessária. Rio de Janeiro: Paz e Terra, 1975.

SCHIPPERS, Huib. Facing the Music. Oxford: Oxford University Press, 2010.

SHEPHERD, John. Musicas Social Text. Cambridge, UK: Polity Press, 1991.

WESTVALL, Maria \& CARSON, Charles, D. Utmanas trygghetszonen? Musikundervisningens roll i det mångkulturella samhället. In: Øivind Varkøy och Johan Söderman:Musik för alla. Filosofiska och didaktiska perspektiv på musik, bildning och samhälle. Lund: Studentlitteratur, 2014, p. 107-119.

YAMAZAKI, Yoshitaka \& KAYES, D. Christopher. An Experiential Approach to Cross-cultural Learning: A Review and Integration of Competencies for Successful Expatriate Adaptation. In: Academy of Management Learning \& Education. Vol. 3 , No.4, 2004, p. 362-379. 